\title{
The Role of Combined Nicotine and Caffeine Administration on the Histological Structure of the Rat Urinary Bladder with a Special Reference to P53
}

\author{
Alhan I Allehaibi ${ }^{1}$, Siham K Abunase ${ }^{1,2 *}$ and Azza I Zaki ${ }^{1,3}$ \\ ${ }^{1}$ Anatomy Department, Faculty of Medicine, King Abdulaziz University, Saudi Arabia \\ ${ }^{2}$ Histology Department, Faculty of Medicine, Ain Shams University, Egypt \\ ${ }^{3}$ Anatomy Department, Faculty of Medicine, Alexandria University, Egypt
}

\begin{abstract}
Background: It is difficult to find microscopic studies that can demonstrate the effect of combined administration of nicotine and caffeine on the mucosa of the rat urinary bladder.

Aim of work: So, the current study aimed at demonstration of histological and p53 immuno-histochemical expression of the mucosa of rat urinary bladder as a marker sharing in process of apoptosis following the combined administration of nicotine and caffeine.

Materials and methods: The animals were divided randomly into 4 groups: control, Nicotine, caffeine and combined Nicotine and Caffeine. The urinary bladder was processed and stained with hematoxylin and eosin stain, histochemically by PAS and immunohistochemically by Anti p53 antibodies.

Results: After nicotine there was apparent increase in the layers of epithelium with intraepithelial lymphocytes. The strong PAS positive reaction of the basal layer together with P53 positive expression of few lamina propria cells was evident. After caffeine, the epithelial layers and mononuclear cells of the lamina propria were increased. There was a marked decrease in the PAS positive reacting cells of the superficial cell layer. The groups that have administered combine caffeine and nicotine; there were focal areas of epithelial erosion with proliferating basal layers. There was a strong PAS positive reaction under the basal layer and p53 positive expression of many lamina propria cells.
\end{abstract}

Conclusion: The present study had concluded that the chronic administration of combined nicotine and caffeine could result in epithelial hyperplasia associated with positive P53 expression in nuclei of lamina propria cells of the urinary bladder mucosa.

Keywords: Nicotine; Caffeine; Urinary bladder; P53; PAS

\section{Introduction}

Reporting that nicotine is a major toxic component of cigarette smoke was done. Also, that the long half-life cotinine, which is the metabolite after nicotine oxidation, could play a significant role in vascular diseases. Authors reported that that chronic administration of nicotine to rats induces cytochrome P-450 together with generation of free radicals in tissues of rats and exerts oxidative tissue injury [1].

Caffeine beverages connected to the family of alkaloids and the methylxanthine team [2]. Caffeine beverages were normally can found in several vegetation, such as coffees, candy legumes and tea. Caffeine has a positive effect on the central neurological system, pulse amount, and breathing. It has feelings changing qualities, and also acts as a light diuretic [3]. Caffeine beverages can found in variety of popular products such as tea, coffee, candy, sodas including pharmacological products as a psycho-stimulant [4].

There is an adverse relationship between fat peroxidation items and the activity of endogenous anti-oxidants, catalase and superoxide dismutase. Which means an increase in the fat peroxidation items lead to a reduction in the activity of endogenous anti-oxidants, catalase and superoxide dismutase. Since the phospholipids in the cell membrane consider as vital for the maintenance and reliability of cell function, the disorder of phospholipids by fat peroxidation is expected to change cell membrane structure, fluidity, transportation and antigenic qualities, all of which has involved in the pathogenesis of organ affection [5].

It was observed that the symptoms in both interstitial and acute cystitis as pain are increased by increase of the urine acidity. This acidity resulted in irritation to the bladder [6,7]. The increased acidity of the urine by coffee intake is through increasing acid metabolites of coffee in the urine [7].

P53 has a role in induction of cell-cycle stopage and apoptosis. It can cause it by activation of a new gene named PUMA ( $\mathrm{p} 53$ upregulated modulator of apoptosis) as one of the proapoptotic genes during transcription [8-10]. Another study stated that, it is able to form both extrinsic receptor death apoptosis and intrinsic mitochondrial [11].

"Apoptosis is the state of programmed cell death that started from a combination of intrinsic and extrinsic signals that pass into a common downstream effector pathway" [12]. The abnormal molecular techniques of apoptosis are crucial in the pathogenesis of malignancy.

*Corresponding author: Abunasef SK, Anatomy Department, Faculty of Medicine, King Abdulaziz University, Saudi Arabia, Tel: 00966543561012; E-mail: abunasef2@hotmail.com

Received November 21, 2015; Accepted June 20, 2017; Published June 28, 2017

Citation: Allehaibi Al, Abunasef SK, Zaki Al (2017) The Role of Combined Nicotine and Caffeine Administration on the Histological Structure of the Rat Urinary Bladder with a Special Reference to P53. J Cytol Histol 8: 455. doi: 10.4172/21577099.1000455

Copyright: (C) 2017 Allehaibi Al, et al. This is an open-access article distributed under the terms of the Creative Commons Attribution License, which permits unrestricted use, distribution, and reproduction in any medium, provided the original author and source are credited. 
This abnormal apoptosis results in long survival of neoplastic cells. "This results in resistance to generally harmful stresses [13]. (It had provided that interplay of several proteins results in either inhibition or activation of the apoptotic cascade) [14]. The tradition of combination of drinking coffee during smoking raised the question about the suspected changes of combination of nicotine and caffeine. Also, it is difficult to find microscopic studies that can demonstrate the effect of combined administration of nicotine and caffeine on the mucosa of the rat urinary bladder. So, the current study aimed at demonstration of histological changes following the combined administration of nicotine and caffeine with a special reference to p53 immunohistochemical expression of the rat urinary bladder mucosa as a marker sharing in the process of apoptosis.

\section{Material and Method}

\section{Drug preparation}

1) A freshly prepared nicotine in normal saline for each group of animals was injected subcutaneously (SC) as $10 \mathrm{mg} / \mathrm{kg}$ body weight 3times/week for 4 weeks to produce a chronic plasma level of nicotine according to a previous study [15]. The prepared solutions were stored in foil-wrapped glass bottle at $4^{\circ} \mathrm{C}$ for just about $4-5$ days. Nicotine hydrogen tartrate was purchased from Sigma (USA).

2) Caffeine anhydrous extra pure (99\%) (CA0150) had purchased from (Scharlau Chemie- Barcelona Spain).

The animals were treated by intraperitoneal injection(IP) of 100 $\mathrm{mg} / \mathrm{kg}$ body weight caffeine dissolved in saline daily for 30 days. The choice of this dose was dependent on the protective results of a biochemical study [16]. The dissolved caffeine was filtered through a disposable sterile filter membrane (Corning incorporated) made in (USA) immediately before injection.

\section{Animals}

Forty two males Wistar rats were obtained from the Animal House, of King Fahd Medical Research Center (KFMRC). The average weight was 200-250 grams and the age of experimental rats was reached to 2-2.5 months old. The experimental animals were randomly divided into four groups, each one including 5 male rats. All groups of experiment were given food and drinking water ad libtum. The experiment was conducted at $23-25^{\circ} \mathrm{C}$ under the umbrella of the ethical approval accomplished by the King Abdulaziz National Committee of the ethical approval.

\section{Study design}

The animals were divided into the following groups:

Group I (Control): The animals were injected with normal saline by the subcutaneous (S/C) 3 times/week and IP daily.

Group II: The animals had unmixed nicotine injection in a dose as previously mentioned.

Group III: The animals caffeine injection as previously mentioned.

Group IV: The animals had nicotine and caffeine injection as previously mentioned.

At the end of the experiment male rats were dissected and the urinary bladder was processed. The histological blocks were cut by a manual microtome in 4-5 $\mu \mathrm{m}$ thickness. Then, the histological sections were stained with hematoxylin and eosin stain and histochemically by PAS. Some sections were stained immuno-histochemically by
Anti p53 antibodies by Ventana Medical Systems on an automated immunostainer (Ventana Medical Systems). After deparaffinization of $5 \mu$ sections, immunohistochemical staining was performed using a streptavidinbiotin peroxidase system with a DAP chromagen and a Mayer,s hematoxylin counterstain. Anti- p53 (Oncogene Science, Uniondale, NY) were used at a 1:200 dilution in antibody diluent (Ventana Medical Systems). Antigen Retrieval was used by putting the slide jar in citrate buffer for 30 seconds in lab microwave. Negative controls (to assure lack of nonspecific staining) were run on each sample by substituting antibody diluent for the antibody. A breast cancer cell line ( $p 53)$ was included in each run as a positive control to assure proper staining and to evaluate the intensity differences in staining.

\section{Results}

\section{Light microscopic results}

H\&E staining: The examined H\&E stained sections from Group I (GI) (Control) showed the different layers of transitional epithelium of rat urinary bladder (Figure 1A). The group II (GII) after nicotine revealed apparent increase in the layers of epithelium. There were intraepithelial lymphocytes. Apparent increase in cells with a pale halo around the nuclei was observed (Figure 1B). The group III (GIII) after caffeine showed apparent increase in the epithelial layers especially in the basal layer with increase in eosinophilia of superficial cells. There was an increase of mononuclear cells of the lamina propria (Figure 1C). In the combine group, there were focal areas of epithelial erosion. The basal layer showed multiple layers of spindle shape cells. The marked increase in the mononuclear cells in the lamina propria and congested small blood vessels were noticed (Figure 1D).

PAS staining: Sections in the rat urinary bladder that was stained histochemically by PAS showed the followings. The sections of the control group showed PAS positive reacting superficial cell layer of the epithelium. The PAS positive reacting basal lamina was observed (Figure 2A). In nicotine treated rats, there was a strong PAS positive

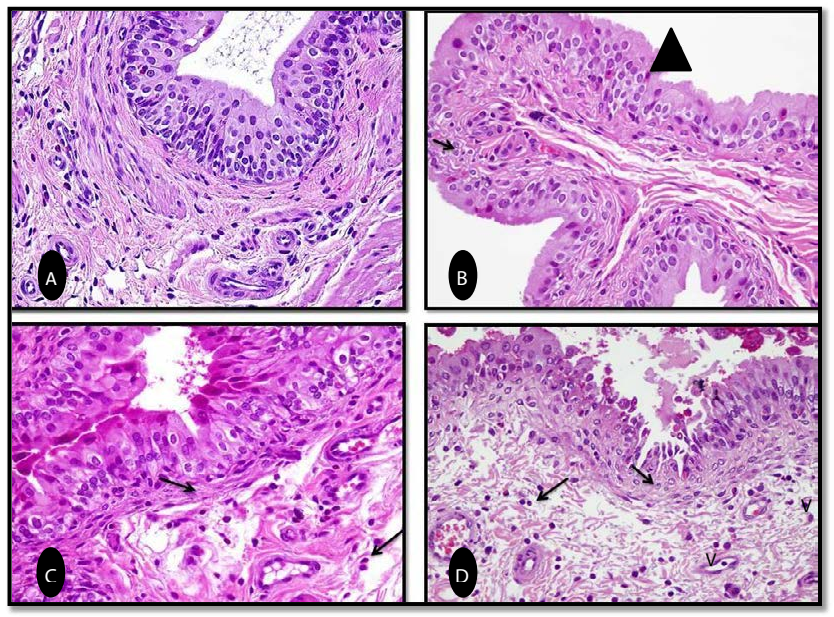

Figure 1: Photomicrographs of the urinary bladder mucosa from different groups showing: A. The transitional epithelium of rat urinary bladder (GI). B. After nicotine (GII), there is apparent increase in the layers of epithelium with intraepithelial lymphocytes (thin arrow) with apparent increase in cells with a pale halo around pycknotic nuclei (arrowhead). C. After caffeine (GIII), there is apparent increase in the epithelial layers especially in the basal layer (arrow) with high eosinophilia of superficial cells. D. Combined group (GIV), Areas of sloughed epithelial cells. The basal layer has multiple layers of proliferating spindle shape cells. Notice the marked increase in the mononuclear cells in the lamina propria (arrow) and congested small blood vessels (v). H\&E x400. 
reaction of the top layer of the epithelium with a strong PAS positive reaction of the basal layer (Figure $2 \mathrm{~B}$ ). Remarkably, in caffeine, there was a decrease in the PAS positive cells reaction of the superficial cell layer (Figure 2C). The group (IV) (combined nicotine and caffeine), there was a notable escalation in the PAS positive reacting cells. The sections displayed the strong PAS positive reaction under the basal layer (Figure 2D).

P53 staining: The stained urinary bladder mucosa by p53 immunostain from different groups showed negative immunoexpression of p53 of both the surface epithelium and lamina propria cells $(0 \%$ of positive cells) in control sections (Figure $3 \mathrm{~A}$ ). In nicotine treated rats, there was a $\mathrm{P} 53$ positive expression of few lamina propria cells (Figure 3B). The caffeine treated rats showed a similar picture to the previous group (Figure $3 \mathrm{C}$ ). In combined treated rats, there was a 553 positive expression of many lamina propria cells (Figure 3D).

\section{Discussion}

In the present study, rats were administered nicotine by subcutaneous injection to ensure the systemic effect. The urinary bladder epithelium following nicotine administration showed hyperplasia indicating increased number of proliferating cells. A similar effect of on the rat urothelium was also recorded by another study on rat and mice after oral administration by Dodmanea et al. [17]. In contrary, Theophilus et al. (2012) [18] recorded no abnormality in the urinary bladders, except for amyloid deposition in the submucosa of one male rat. Their results may be due the short duration of the experiment.

The detected hyperplasia was associated with thickening of the basement membrane under the epithelium as indicated by the strong PAS positive reaction of the basal layer suggesting the deposition of glycoprotein. Also, the use of p53 as an apoptotic marker with no expression except for $\mathrm{p} 53$ positive expression of few lamina propria cells suggested that nicotine has a mitogenic effect rather that a cytotoxic effect on the proliferating epithelium. The same suggestion was previously mentioned in human studies by Cohen [19] and animal studies [20,21]. However, the present results also detected presence of

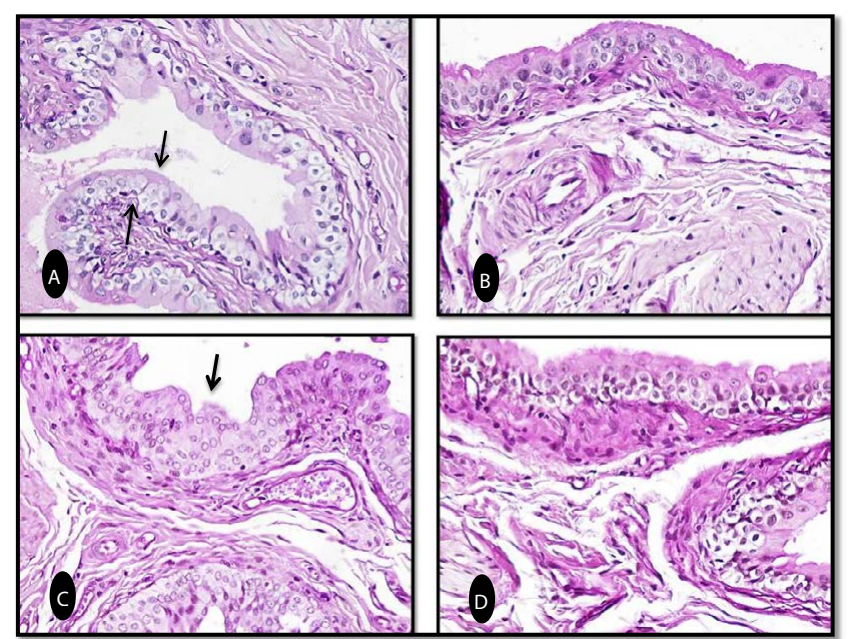

Figure 2: Photomicrographs of the urinary bladder mucosa from different groups: A. GI: PAS positive reacting superficial cell layer of the epithelium $(\rightarrow)$ and basal lamina. B. In nicotine treated rats (GII), nearly similar to control. C. In caffeine (GIII), there is a marked decrease in the PAS positive reacting cells of the superficial layer (arrow). D. Combined group (GIV), there is a marked increase in the PAS positive reacting cells and basal lamina. PAS $\times 400$.

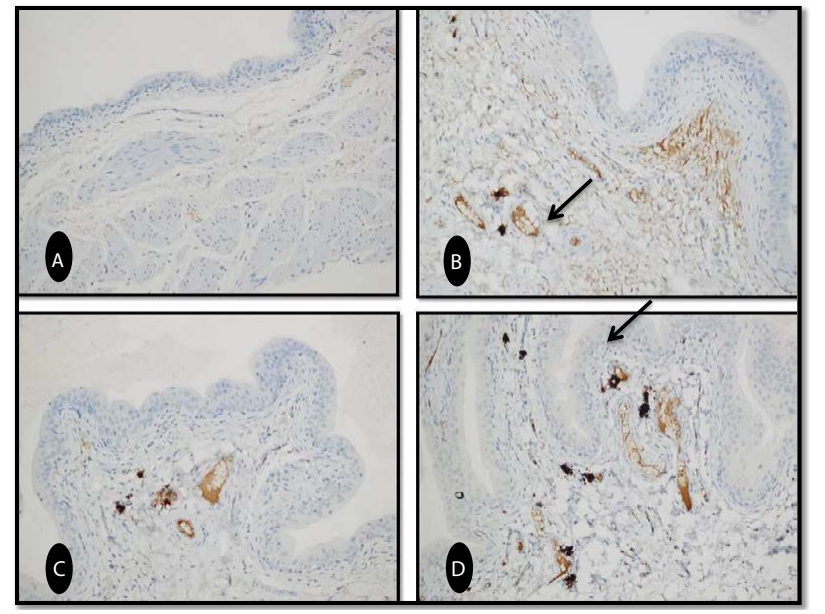

Figure 3: Photomicrographs of the urinary bladder mucosa from different groups: In GI, the surface epithelium and lamina propria cells showed negative immunoexpression of p53. B. GII, there is a P53 positive expression of few lamina propria cells $(\rightarrow)$. C. GIII, a similar picture to the GII. D. GIV, there is a P53 positive expression of many lamina propria cells $(\leftarrow)$. (IHC for p53 x200).

intraepithelial lymphocytes, which was clear in some sections of the urinary bladder after nicotine. It was considered a common reactive inflammatory disorder, which is constantly recurring [22,23].

The epithelial layers and mononuclear cells of the lamina propria were increased after caffeine only together with marked decrease in the PAS positive reacting cells of the superficial cell layer suggesting that there were tissue wasting and negative nitrogen balance. This suggestion was predicted as a result of accumulation of xanthurenic acid in the extra hepatic tissues resulting in resulting in accumulation of kynurenine and 3-hydroxy kynurenine [24].

The group that have administered combine caffeine and nicotine, there were focal areas of epithelial erosion with proliferating basal layers. This finding suggesting that caffeine has a weak opposing effect with nicotine. This also ensured by the strong PAS positive reaction under the basal layer and p53 positive expression of many lamina propria cells simulating the nicotine group. These results may be due to the excretion of cotinine (the primary metabolite of nicotine). Nicotine is extensively metabolized in the body, mainly to cotinine (70-80\% of nicotine). These metabolites are excreted in urine primarily [25]. Urinary levels of cotinine are higher than that of the blood levels [26]. Studies in animals showed a dose-dependent increase in cotinine levels in the urine. Excretion of unchanged nicotine in urine is reach to $15 \%$ of administered nicotine [25].

The P53 is used for its function in induction of apoptosis and cellcycle arrest. When proapoptotic genes activate during transcription, apoptosis can occur. It has the ability to induce both intrinsic mitochondrial and extrinsic death-receptor apoptosis [9]. So, its minimal negative expression in the urothelium and lamina propria cells ensures that nicotine and caffeine could not be a cause for malignant changes that can be a result of chronic inflammation.

\section{Conclusion}

The present study had concluded that the chronic administration of combined nicotine and caffeine could result in epithelial hyperplasia associated with positive P53 expression in nuclei of lamina propria cells of the urinary bladder mucosa. 
Citation: Allehaibi Al, Abunasef SK, Zaki Al (2017) The Role of Combined Nicotine and Caffeine Administration on the Histological Structure of the Rat Urinary Bladder with a Special Reference to P53. J Cytol Histol 8: 455. doi: 10.4172/2157-7099.1000455

\section{Conflict of Interest}

Authors declared no conflict of interest.

\section{References}

1. Husain K (2001) "Chronic ethanol and nicotine interaction on rat tissue antioxidant defense system." Alcohol 25: 89-97.

2. Bolignano D (2007) "Caffeine and the Kidney: What Evidence Right Now?" Journal of Renal Nutrition 17: 225-234.

3. Helmenstine A (2008) "What Is Caffeine and how does It Work?" About.com: Chemistry: CaffeineChemistry.

4. Sener G, Sehirli O, Ipci Y, Cetinel S, Cikler E, Gedik N, Alican I (2005) "Protective effects of taurine against nicotine-induced oxidative damage of rat urinary bladder and kidney." Pharmacology 74: 37-44.

5. Bade JJ, Peeters JM, Mensink HJ (1997) Is the diet of patients with interstitial cystitis related to their disease? European Urology. 32: 179-183.

6. Brown SE (2003) Excessive acidity may aggravate urinary disorders. Total Health. 25: 22-23.

7. Olthos MR, Hollman PCH, Katan MB (2001) Chlorogenic acid and cafeeic acid are absorbed in humans. Journal of Nutrition 131: 66-71.

8. Nakano K, Vousden KH, PUMA (2001) A novel proapoptotic gene, is induced by P53. Mol Cell 7: 683-694.

9. Yu J, Zhang L, Hwang PM, Hwang PM, Kinzler KW, Vogelstein B (2001) PUMA induces the rapid apoptosis of colorectal cancer cells. Mol Cell 7: 673-682.

10. Karam JA, Lotan Y, Karakiewicz PI, Ashfaq R, Sagalowsky Al, et al. (2007) Use of combined apoptosis biomarkers for prediction of bladder cancer recurrence and mortality after radical cystectomy. Lancet Oncol 8: 128-136.

11. Vousden KH. (2000) P53: death star. Cell 103: 691-694.

12. McKnight JJ, Gray SB, O'Kane HF (2005) Apoptosis and chemotherapy for bladder cancer. J Urol 173: 683-690.

13. Reed JC (1999) Dysregulation of apoptosis in cancer. J Clin Oncol 17: 2941-2953.
14. Akhtar M, Gallagher L, Rohan S (2006) Survivin: role in diagnosis, prognosis, and treatment of bladder cancer. Adv Anat Pathol 13: 122-126.

15. Leach PT, Cordero KA, Gould TJ (2013) The effects of acute nicotine, chronic nicotine, and withdrawal from chronic nicotine on performance of a cued appetitive response. Behav Neurosci 127: 303-310.

16. Abunasef SK, Amin HA, Abdel-Hamid GA (2014) A histological and immunohistochemical study of beta cells in streptozotocin diabetic rats treated with caffeine. Folia histochemica et cytobiologica 52: 42-50.

17. Dodmanea PR, Arnolda LL, Penningtona KL, Cohen SM (2014) Orally administered nicotine induces urothelial hyperplasia in rats and mice. Toxicology 315: 49- 54

18. Theophilus EH, Hayes JR, Potts RJ, Garner CD (2012) "Toxicological evaluation of smokeless tobacco: 90-day rodent feeding studies." Exp Toxicol Pathol 64: 15-24.

19. Cohen SM (1998) Urinary bladder carcinogenesis. Toxicol. Pathol. 26: 121-127.

20. Apasov SG, Blackburn MR, Kellems RE, Smith PT, Sitkovsky MV (2001) Adenosine deaminase deficiency increases thymic apoptosis and causes defective T cell receptor signalling. J Clin Invest 108: 131-141.

21. Ashakumary L, Vijayammal PL (1996) Additive effect of alcohol and nicotine on LPO and antioxidant defense mechanism in rats. J Appl Toxi-col 16: 305-308.

22. Kagami K, Morita H, Onda K, Hirano T, Oka K (2008) Protective effect of caffeine on streptozotocin-induced beta-cell damage in rats JPP 60: 1161-1165.

23. Grignon DJ, Sakr W (1995) Inflammatory and other conditions that can mimic carcinoma in the urinary bladder. Pathol Annu 30: 95-122.

24. Chatterjee MN, Shinde R (2000) Metabolism of proteins and amino acids. In Textbook of Medical Biochemistry ( $5^{\text {th }}$ Edition) Vij, J.P and Yadav, R.K (eds.) JAYPEE Brothers Medical publishers (P) Ltd, New Delhi 7: 395-452.

25. Hukkanen J, Jacob 3rd P, Benowitz NL (2005) Metabolism and disposition kineticsof nicotine. Pharmacol. Rev 57: 79-115.

26. Benowitz NL, Dains KM, Dempsey D, Herrera B, Yu L, et al. (2009) Urine nicotine metabolite concentrations in relation to plasma cotinine during lowlevel nicotine exposure. Nicotine Tob. Res 11: 954-960. 